\title{
Sexual life in subjects with intellectual disability
}

\author{
Loïse Conod, BSc, (I) Laurent Servais, MD, PhD. (I)
}

\begin{abstract}
Conod L, Servais L.
Sexual life in subjects with intellectual disability. Salud Publica Mex 2008;50 suppl 2:S230-S238.
\end{abstract}

\begin{abstract}
During the last decades, the expectancies towards sexual life of people with intellectual disability have been more and more recognized by researchers, clinicians, caregivers and parents. These expectancies, that largely depend on socio-cultural and personal factors, such as the level of disability, must be supported in order to help people with intellectual disability to reach the best quality of life as possible. Therefore, it is important to identify every patient's and resident's personal expectancies towards sexuality and which medical and educative support he/she needs according to his/her disability and co-morbidity. The aim of the present paper is to review the different research works conducted in this area.
\end{abstract}

Key words: sexuality; contraception; sterilization; mental retardation; intellectual disability; sexual abuse; sexually transmitted infections;AIDS; hygiene management

\author{
Conod L, Servais L. \\ La vida sexual de las personas con discapacidad intelectual. \\ Salud Publica Mex 2008;50 supl 2:S230-S238.
}

\section{Resumen}

En décadas recientes los investigadores, médicos, personal de salud y padres de las personas con discapacidad intelectual han venido reconociendo cada vez más la expectativa de una vida sexual para éstas últimas. Estas expectativas, que en gran medida dependen de factores personales y socioculturales, como por ejemplo, el grado de discapacidad, merecen apoyarse a fin de que las personas con discapacidad intelectual alcancen la mejor calidad de vida posible. Por lo tanto, es importante identificar las expectativas individuales de cada paciente con respecto a su sexualidad, para así poder saber qué clase de apoyo médico o educativo necesita de acuerdo a su discapacidad y comorbilidad. La finalidad del presente estudio será revisar las diversas investigaciones efectuadas en este campo.

Palabras clave: sexualidad; anticoncepción; esterilización; retraso mental; discapacidad intelectual; abuso sexual; infecciones de transmisión sexual; SIDA; manejo de la higiene
C aregivers and clinicians know that the sexuality of persons with intellectual disabilities (ID) remains a sensitive subject for many parents and many institutions. Fortunately, in the scientific literature, many studies have been published for more than 30 years to assess medical and educational issues regarding the sexual health of persons with intellectual disabilities. Because of famous medico-legal cases ${ }^{1}$ or controversies about systematic sterilizations in different Western countries, ${ }^{2}$ a number of case reports, editorials, viewpoints, ethical,

(I) Service de Neurologie Pédiatrique et des Maladies Métaboliques. Hôpital Robert Debré. Paris, France. 
legal and historical reviews have also been published concerning hysterectomy or any form of surgical sterilization, so that the debate has too often been "To sterilize or not to sterilize". Indeed, because of suspected poor medical compliance and/or vulnerability to sexual assault, persons with intellectual disabilities are often considered candidates for surgical sterilization. Parents and caregivers have expressed a strong preference for these methods, ${ }^{3-6}$ and there is a high satisfaction rate when they are performed. ${ }^{7,8}$ Unwanted pregnancy is definitely not the sole problem that may arise from the sexual activity of persons with intellectual disabilities. Sexually transmitted infections (STI), abuse or public offences constitute other potential problems that are often neglected since (surgical) contraception may give the wrong impression that "there is no danger anymore". In 2007, the question is not whether persons with intellectual disabilities have a sexuality or if they have the right to live it. They do. The question is "How may clinicians, caregivers and parents help persons with intellectual disabilities to live their own sexuality? What are the specific needs of intellectually disabled patients, and how can they be assessed for preventive health?" The first part of the answer resides in the knowledge that the problem exists, that it is intrinsically complex, and that it cannot be properly dealt with by simplistic considerations or radical ukases from the legal guardian of the patient. The aim of this paper is to review the different research works conducted to define the expectancies and needs of persons with intellectual disabilities in the area of sexuality and the potential solutions that have been evaluated.

\section{People's expectancies}

The expectancies of persons with intellectual disabilities towards sexuality vary considerably according to their level of disability. Some studies have specifically addressed the sexual activity of persons with intellectual disabilities according to their disability level. Through parents and caregivers' interviews, Chamberlain and coworkers ${ }^{9}$ found that half of the 11 to 23 year-old mildly disabled women attending a multiservice adolescent clinic in Cincinnati, USA, and who lived in the community, had had consenting sexual intercourse. This was the case for only 32 and $9 \%$ of women with moderate and severe disability, respectively. According to these authors, the proportion of sexual activity in women with mild disability was similar to that of the general population after adjustment for age and race. Similarity between mildly disabled patients and the general population in terms of sexual activity was also reported by others. ${ }^{10-13}$ More recently, Mc Gillivary ${ }^{14}$ interviewed 60 adults (35 men and 25 women) with mild to moderate intellectual disability living in the community. She found that 18 and $42 \%$ of the study subjects reported that they were currently or previously sexually active, respectively. In 2002, we published a study concerning the determinants of contraception among intellectually disabled women attending the state-funded facilities of the Belgian Region of Brussels and the neighboring Province of Walloon Brabant. ${ }^{15}$ Data from 397 women were collected (some data herein presented were not published and were extracted from our data base for this review). In this study, we distinguished between "previous consenting sexual intercourse" and "previous boyfriend" for each person. For many of the mildly and severely disabled women, romantic relationships were frequently noticed by the staff, whilst the person and / or her boyfriend had limited or no notion of what sexual intercourse was. The daily and structural organization of the institution did not allow the privacy required for a sexual relationship.

Because of the lower sexual activity of people with moderate and severe intellectual disability, studies that have assessed the overall sexual activity of the intellectually disabled population with no mention of disability level have demonstrated an overall lower sexual activity. For instance, through institution's mail interviews, Diederich and Graecen ${ }^{16}$ extrapolated that $41 \%$ of intellectually disabled adults institutionalized in the region of Paris had ever had sexual intercourse. With a similar methodology, Gust and coworkers ${ }^{17}$ reported that $48 \%$ of the directors of state residential facilities with fewer than $50 \%$ of profoundly intellectually disabled subjects in the USA considered that sexual relations between patients occur sometimes, whereas $15 \%$ estimated that they occur often.

These different studies have assessed the previous or supposed sexual or romantic activity of persons with intellectual disabilities, as reported by parents and/or caregivers, but these activities not only depend upon the expectancies of the persons, but also upon the opportunity provided by their life milieu. In our study, $82 \%$ of mildly disabled women living in a coeducational facility previously experienced sexual intercourse, whereas only $4 \%$ of those living in a non-coeducational facility did so. In the study of Mc Gillivary, ${ }^{14} 46 \%$ of mildly and moderately intellectually disabled people with no prior sexual experience communicated that they intended to become sexually active as soon as the opportunity presented. McCabe ${ }^{18}$ reported similar findings in another group of 60 community dwelling Australians with mild ID. Approximately $58 \%$ of participants had previously experienced sexual intercourse, and 31\% were currently sexually active, with frequency ranging from almost never to very often. Individuals with ID 
were significantly less sexually active than peers with physical disabilities and the general population.

Pueschel and Scola ${ }^{19}$ interviewed the parents of 73 teenagers with Down syndrome (36 males and 37 females). Despite that over half the teenagers had expressed an interest in the opposite sex and that masturbation had been noticed in $40 \%$ of the males and $22 \%$ of the females, only four parents reported that their son or daughter ever mentioned a desire for sexual intercourse. The discrepancy with the results of Mc Gillivary ${ }^{14}$ is more likely due to methodological differences between both studies (patients' versus parents' interviews) than from a specificity of Down syndrome in term of sexual expectancies.

It must be noted that the different studies listed here have been conducted in developed countries. In many developing countries, sexual activity outside the marriage is much less socially valorized, and therefore, it would not be surprising to observe a significant difference in the expectancies of people with intellectual disability and their family towards sexuality.

Where ever in the world, there is a paucity of studies that have assessed in a large and representative sample what persons with intellectual disabilities themselves expect from sexuality in terms of sexual intercourse as well as affective relationships, marriage, and child raising. Also, the determinants of these expectancies (i.e. disability level, life milieu, previous sex education, gender, etc.) are not documented.

In the daily practice, to explore what a given patient expects from his or her sexuality is essential when providing preventive care. Indeed, this will further determinate his/her specific needs and therefore the educative and medical attitude needed. We have illustrated, through different case reports of persons with intellectual disabilities, that the concept of what sexual intercourse is, and what both partners want from their affective relationship may strongly vary. This could lead to some form of sexual abuse if not detected and dealt with properly. ${ }^{20}$ From these cases, we concluded that it is important to provide consultations where each partner will have the opportunity and time to freely express his/her wishes about sexuality through his/her own words, when intellectually disabled couples initiate common life.

\section{Patient's needs}

From this literature review, it appears that hygiene management, general gynecological care compliance, Sexually Transmitted Infections (STI), abuse, and unwanted pregnancy prevention constitute different skill areas where the adaptive functioning of persons with intellec- tual disabilities may require specific educative and/or medical management. Since the adaptive functioning of the persons with intellectual disabilities widely depends on the disability level and also on the potential neurological, psychiatric or general co-morbidity, the support needs and the potential solution that may be proposed will greatly vary from one person to another.

\section{Hygiene}

Difficulty in managing menstrual flow constitutes a common problem amongst intellectually disabled women, especially the most severely disabled. Chamberlain and coworkers ${ }^{9}$ reported that 88,44 and $27 \%$ of severely, moderately and mildly disabled women, respectively, experienced hygiene difficulty during their menstrual periods. Elkins and coworkers ${ }^{5}$ noticed that a hygiene problem was the reason for referral of $22 \%$ of intellectually disabled women to the interdisciplinary clinic of reproductive health in Memphis, USA. In our survey of 397 women with intellectual disability, ${ }_{1}^{15}$ we found that the prevalence of hygiene problems was 14, 2 and $1 \%$ in severely, moderately and mildly disabled women, respectively. The differences in prevalence between our study and the other two studies ${ }^{5,9}$ reside in the difference in case selections. Indeed, those two studies were conducted in gynecologic clinics devoted to adolescents or persons with intellectual disabilities living in the community, whereas our study concerned all women attending the state-funded facilities in a given region.

The increased prevalence of hygiene problems in severely and profoundly disabled women is not only related to the increased cognitive impairment of these women, but also to motor disability, which is frequently associated with severe and profound intellectual disability. In our study, problems in menstrual period management were 4.2 times more frequent in profound and severely disabled persons who presented associated motor impairment than in women with the same level of intellectual disability, but without motor impairment.

Different approaches have attempted to provide support in hygiene management. It seems that behavioral education may help greatly, especially for women with mild and moderate disability. ${ }^{21-24}$ These approaches may be very helpful when patients view their menstrual periods as a sign of normalcy, similar to their mothers and sisters. Pharmacological approaches include oral lynestrenol, ${ }^{25}$ low-dose oral contraceptives that diminish menstrual flow, or depomedroxyprogesterone acetate (DMPA) injected every three months.,26 In our study, DMPA injections were used by $17.6 \%$ of patients. ${ }^{15}$ 
Amongst severely and profoundly disabled women, it was the first contraceptive method, used by $42 \%$ of the patients under contraception. This demonstrates that the purpose of this method goes far beyond simple contraception. Progestin implants are increasingly replacing DMPA, with similar effect on menstrual flow.

Endometrial ablation has been proposed as a therapeutic option when pharmacological therapy is not sufficient or contraindicated..$^{26}$ Some have advocated hysterectomy as a first choice method to cease menstrual flow, ${ }^{7}$ especially in the context of developing countries. For instance, Shet and Malpani ${ }^{27}$ reported that vaginal hysterectomies performed on 60 Indian women with ID resulted in "no significant complications", and parents were "very pleased with the smooth postoperative recovery". However, where behavioral and pharmacological therapies are available, this approach as a first line treatment seems to be out of use. Indeed, in a case series of 82 persons with moderately and mildly intellectual disabilities consulting the gynecologist for problems related to menstrual periods, Grover ${ }^{28}$ found that hygiene advice and pharmacological therapy could manage the problems of 80 of the patients. The two remaining patients benefited ultimately from an endometrial ablation for one, and a hysterectomy for the other.

Other problems related to menstrual periods in intellectually disabled women essentially consist of behavioral trouble. Elkins and coworkers ${ }^{5}$ reported a $32 \%$ rate of premenstrual syndrome, including increased autistic behavior, irritability, restlessness, and seizures. Because of their inability to express their uncomfortable sensations, women with severe and profound disability may experience very severe premenstrual syndrome. ${ }^{29}$ Grover $^{28}$ identified this as the main clinical problem leading to referral to the gynecologist in eight of her 107 patient's series. DMPA or low-dose oral contraceptives seem to be efficient treatments. ${ }^{5}$ Grover ${ }^{28}$ has proposed non-steroidal anti-inflammatory drugs as a first line treatment to manage dysmenorrhoea or behavior changes to reflect pain in the absence of a need for contraception.

\section{Prevention of sexual abuse}

Persons with intellectual disabilities constitute potential victims of sexual abuse. Women with mild intellectual disability seem to be at increased risk. Chamberlain and coworkers ${ }^{9}$ reported a $25 \%$ prevalence of sexual abuse in intellectually disabled women living in the community. These abuses concerned mildly disabled women in $63 \%$ of cases. A similar finding was reported by Elkins et al..$^{5}$ In these author's series of intellectu- ally disabled outpatients, 10 in 37 [27\%] intellectually disabled women had been abused, seven of these 10 being mildly disabled. We found that women living in the community presented a 3.5 times increased risk to have experienced sexual abuse than women living in an institution. ${ }^{15}$ In a study by Huovinen, ${ }^{25}$ suspicion of sexual abuse was only $1.2 \%$.

The intellectual ability of the abuser depends upon the studied population. Indeed, in outpatients studies, ${ }^{9}$ the abuse was incest in $41 \%$ of cases, and the abuser was nearly never intellectually disabled himself $(4 \%)$. In strong contrast, US directors of a state facility for inpatients with intellectual disability reported that the abuser was a patient of the institution in $63 \%$ of cases. ${ }^{17}$

The reasons for this increased prevalence of sexual abuse against intellectually disabled women are multiple. Different authors have proposed that the passive, obedient and affectionate behavior presented by many subjects may constitute a risk factor. ${ }^{16,26,30}$ The easiness for the abuser to perpetrate rapes on non mobile patients, the difficulties of the victim to understand and to express what happened, and the proximity required for hygiene care constitute other reasons that may increase the risk of abuse against intellectually disabled women.

Prevention of sexual abuse must pass through sexual education of the patients. Many studies conducted in the $70^{\prime}$ s and $80^{\prime}$ 's have demonstrated that persons with intellectual disabilities have a very low level of knowledge in reproductive health (for a review, see ${ }^{31}$ ). Lindsay and coworkers ${ }^{32}$ and Mc Gillivary ${ }^{14}$ have more recently illustrated the naivety of persons with intellectual disabilities in terms of sexuality before any sex education. Parents' counseling and global approach of patient's reproductive health concern also constitute two essential issues. Indeed, many caregivers or clinicians fear that an approach of reproductive health problems restricted to pregnancy prevention could constitute a risk of sexual abuse and STI transmission, since the patients could wrongly be considered as "presenting no risk for sexuality" by her parents or guardians. $5,15,16,20,26,33,34$

While persons with intellectual disability constitute potential targets for sexual abusers, they may also commit sexual offences or abuse. ${ }^{35}$ Potential risk factors, such as personal experience of sexual abuse as victim, ${ }^{36}$ impulsiveness, ${ }^{37}$ or low anxiety ${ }^{38}$ have been identified by the same group of authors. It seems that sexual abuse is particularly frequent among people with fetal alcohol syndrome. ${ }^{39}$ Different social factors and increased prevalence of the risk factors described above could contribute to this high occurrence of sexual abuse in fetal alcohol syndrome. Even if much more 
frequent among males, sexual abuse is not limited to them. Indeed, characteristics and outcome of women with intellectual disability who committed sexual abuse have been described recently. ${ }^{40}$ In this study, it appears that the prevalence of previous sexual abuse as victim and associated mental illness is especially high (61\% and $67 \%$, respectively). Level of re-offending seems lower in female than in male offenders, and depends on the length of treatment. ${ }^{41}$

\section{Prevention of STI}

Despite the overall lower sexual activity of persons with moderate and severe intellectual disabilities, different risk factors for STI have been identified in them. First, people with intellectual disability constitute potential victims of sexual abuse, as described above. Virgin cleansing, the wrong belief that people who have a STI can rid themselves of the condition by transferring the infective organism through sexual intercourse with a virgin, targets women with intellectual disability, who are assumed to be virgins. ${ }^{42,43}$ Smith $^{44}$ reported that brothels in Victorian England were "stocked with intellectually disabled 'virgins' because it was believed that a syphilitic man could lose the infection by having sex with them". However, figures lack to determine the role of such practice in the spreading of STI amongst persons with intellectual disabilities. In developing countries, the poverty of mildly disabled women and the social sanction against marrying a disabled person may lead these women to be involved in a series of unstable relationships. ${ }^{45}$ Low levels of knowledge about STI transmission may also contribute to increase the vulnerability of people with intellectual disability. For instance, Mc Gillivary ${ }^{14}$ reported that $68 \%$ of the 60 mildly / moderately disabled persons she interviewed about AIDS knowledge believe that taking oral contraceptive agents lowers the risk of contracting AIDS, and that one only gets AIDS if unlucky. Finally, homosexuality is commonly reported amongst persons with intellectual disabilities, ${ }^{17,35,46}$ but nothing indicates that it is more frequent than in the overall population. Moreover, from a survey of 19 men with intellectual disability who had been engaged in a homosexual relationship and who were referred to a Sex Education Team in England, Thompson ${ }^{46}$ concluded that the participation of men with intellectual disability in a homosexual relationship was for reasons other than sexual satisfaction.

Most frequent and severe diseases that may be transmitted through sexual intercourse, such as AIDS or hepatitis B, may also be transmitted through minor blood exchange. Therefore, the prevalence of these STI amongst persons with intellectual disabilities not only results from their sexual activity or potential sexual abuse, but also from the exchange of infected material that may occur from naivety. Transmission of the infective agent may also result from blood effusion caused by behavioral trouble such as aggression or self-mutilation. In addition, because of immunological impairment, patients with Down syndrome are a risk group for hepatitis B virus (HBV) infection and frequently suffer from chronic infection. They constitute therefore a potential risk for the institution where they live. Given its severity and its prevalence, hepatitis B is the first STI to consider in persons with intellectual disabilities. In a study conducted in a Danish institution, Lunding and coworkers ${ }^{47}$ described the serological prevalence of hepatitis B in 126 persons with intellectual disabilities, 20 of them had Down syndrome. They found that $55 \%$ of people with Down syndrome were anti-HBc-positive (which indicates a previous contact with the virus) and $30 \%$ were HBsAg-positive (which indicates ongoing infection). These figures were 32 and $3.8 \%$ respectively, among other residents. In other studies conducted in institutionalized patients since 1990 in Brazil, Belgium, England, Spain, New Zealand, or South Africa, prevalence of hepatitis $B$ serological markers varied from 12 to $61 \%$, with increased rates amongst patients with Down syndrome. ${ }^{48-55}$ One study conducted in 41 institutionalized patients in Finland found a much lower rate of 2 per cent. ${ }^{56}$ In a cross sectional study conducted in a residential institution for intellectually disabled in New Zealand, Stehr-Green and coworkers ${ }^{49}$ demonstrated that residents' risk of being infected increased by $17 \%$ for each additional year they had lived in this institution. In outpatients, seroprevalence is lower, between 9.3 and $11 \%, 57,58$ especially in children where it is estimated to be between 4 and 19.4\%. ${ }^{59-61}$ One study failed to point out any significant differences between outpatients with Down syndrome and a global population control group. ${ }^{62}$

At the beginning of the 90 's, different studies conducted to assess AIDS prevalence amongst intellectually disabled people failed to detect any cases. ${ }^{63,64}$ However, through a national survey mailed to departments providing services to persons with intellectual disabilities in the USA, Marchetti and coworkers ${ }^{65}$ reported 45 persons with intellectual disabilities infected with HIV and seven who were symptomatic. The same authors conducted a follow-up study two years later and reported 98 cases for the same population surveyed. ${ }^{66}$ Surprisingly, another national survey mailed to state residential facilities in 2003 failed to detect any case of AIDS among persons with intellectual disabilities. ${ }^{17}$ Since it should be surprising that intellectually disabled people in USA would be the sole population in 
the world where AIDS would have been completely eradicated, this accurately points out the limitation of the methodology that consists in mailing questionnaires to institutions' directors in regards to such a delicate issue. In Europe, different studies reported cases of AIDS in institutionalized patients since 1996. Ramos-Ibanez and coworkers reported 84 patients with intellectual disability in Castille and Leon (Spain) with a positive serology for HIV. ${ }^{67}$ From a mail-survey with a design similar to the American studies described above, ${ }^{17,65}$ Diederich and Graecen ${ }^{16}$ reported that $11 \%$ of French institutions had once been confronted with AIDS in one of their residents. These results are difficult to interpret, as it is impossible to infer from them an even approximate prevalence rate.

Huovinen ${ }^{25}$ found that pelvic inflammatory disease and condylomata acuminata were less frequent in intellectually disabled than in controls and attributed this difference to a lower sexual activity in the group of disabled patients. Other STI such as genital herpes or syphilis seem to be very rare. ${ }^{17}$

In 2005, the sole STI that may be prevented otherwise than through sex education is hepatitis B. Indeed, hepatitis B prevention may be achieved by immunization of caregivers and persons with intellectual disabilities, especially if Down syndrome constitutes the origin of disability. The immunization of persons with intellectual disabilities should also be achieved, even when the contact between the patient and his/her family is limited to weekend and/or holiday time, since relatives of seropositive patients present a 7.6 times higher risk to present a seroconversion than relatives of seronegative inpatients. ${ }^{68}$ Such immunization programs have already been successfully conducted. For instance, Vellinga and coworkers ${ }^{69}$ have tested the long-term effectiveness of hepatitis B vaccination in 105 institutionalized persons with intellectual disabilities. After 11 years, only two patients seroconverted to anti$\mathrm{HBc}$ positivity without becoming carriers or ill, which demonstrates the efficacy of systematic immunization in institutionalized patients with intellectual disability. It seems that such systematic immunization program should target children before school entrance. Indeed, a study conducted in a Spanish school for intellectually disabled children ${ }^{70}$ demonstrated that the duration of stay at school since the initial entrance constitutes a risk factor for hepatitis B infection. This strongly suggests that to achieve a maximum efficiency, immunization should be performed as soon as possible, ideally before school entrance, especially if the origin of handicap is Down syndrome. ${ }^{71}$ The efficacy of immunization through anti-HBs titration should be carefully checked, especially in male or older people with Down syndrome, who seem to present a lower response to standard immunization. . $0,72,73^{-73}$

Condom use by persons with intellectual disabilities requires adapted sex education, since a large majority $\left(87 \%\right.$ in the study of Mc Gillivary $\left.{ }^{14}\right)$ of persons with intellectual disabilities have nil or minimal understanding of how to use a condom correctly. In a recent survey conducted in 115 of the 168 residential facilities for individuals with intellectual disability in the USA, Gust and coworkers ${ }^{17}$ reported that $28 \%$ of directors of facilities with fewer than $50 \%$ of profoundly disabled persons considered that the use of condom by the patients occurred "sometimes" and 2\% "often". Different educative programs ${ }^{74}$ have been proposed in this purpose. Whether these programs may efficiently lead to significant behavioral change in the real life is difficult to ascertain. Lindsay and coworkers ${ }^{75}$ have demonstrated that theoretical notions acquired during a sex education program may be consistently understood and retained by the majority of adults with a mild or moderate deficiency. The availability of such programs in the facilities for persons with intellectual disabilities is increasing through the years. In the study of Gust and coworkers, ${ }^{17}$ all directors affirmed that mildly disabled patients were offered sex education, whereas $84 \%$ and $63 \%$ of the directors answered "yes" to the same question regarding moderately and severely disabled patients, respectively. From the same survey, it appears that condoms were available at the institution health clinic in $61 \%$ of the facilities.

\section{Prevention of unwanted pregnancy}

To discuss the potential risk for the persons with intellectual disabilities' offspring is far beyond the scope of this review. This risk exists, and largely depends on the origin of the disability, the ability of patients to raise a child and the social support that they may receive in this task. Medical attitude towards or against child wishing of persons with intellectual disabilities is largely driven by personal ethical consideration, but also by the legal context. Thus, this chapter will deal with the prevention of unwanted pregnancy. It must be noted that desired pregnancy is not a common event in persons with intellectual disabilities. Chamberlain and coworkers ${ }^{9}$ reported six cases in their 84 patients studied. Huovinen ${ }^{25}$ reported that the number of pregnancies in a series of 255 intellectually disabled women was 118 times lower than in a group control of women without intellectual disability. In the 300 women series published by Mc Neely and Elkins, ${ }^{24}$ only two had previously delivered. In the national survey of Gust and coworkers ${ }^{17}$ only $2.8 \%$ of the responding directors reported that pregnancy oc- 
curred once in their institution. Finally, in our study, ${ }^{15}$ only $1 \%$ of patients had been previously pregnant.

Except for some genetic syndrome, most of intellectual disability origins do not impair fertility per se. Fertility is decreased in Down's syndrome since paternity is exceptional ${ }^{76}$ and pregnancy remains very rare. ${ }^{29,77,78}$ Other syndromes including hormonal problems or hypogonadism, such as Prader-Willi syndrome, have impaired fertility, even if anecdotic cases of pregnancy have been reported..$^{79}$

Most data concerning the contraception of intellectually disabled women refer to population attending a same gynecologist $\mathrm{t}^{25,28}$ or clinic ${ }^{5,9}$ and therefore essentially reflect the practice of the gynecologist or clinic. Mailsurveys have also been conducted, where institutions' directors have been asked to estimate how often the different contraceptive methods are used in their institutions. ${ }^{16,17}$ At the individual level, these data are difficult to interpret and cannot help to understand the factors that are associated with the use of one method or another. Therefore, we conducted a population-based study that assessed the contraceptive methods used by intellectually disabled women attending state-funded facilities and the different factors associated with an increased or decreased use of these methods. ${ }^{15,34}$ Overall, we found that $40.8 \%$ of intellectually disabled women did not use any contraceptive methods, whilst 22.2\% were sterilized (nearly all by tubal ligation), 18\% used oral contraceptive agents, $17.6 \%$ used DMPA and $1 \%$ had an intrauterine device. Very few factors, and actually none of the medical ones (age, seizures, overweight, inductive drugs intake, tobacco consumption, etc.) were correlated with an increased use of one method or another. Being sterilized was strongly dependent on institutional policy concerning contraception and sexual relationships, but was not correlated with the age of the persons, as it is in the general population. ${ }^{34}$ In another study covering a smaller but different population of adult intellectually disabled women, we even found an inverse relationship between age and sterilization prevalence. ${ }^{33}$

Contraceptive management is a medical act. Therefore, medical indications and contra-indications should be respected in priority when prescribing contraception to an intellectually disabled woman. For instance, oral contraceptive agents should be used cautiously in women older than 35, especially if overweight or tobacco consuming. With the notable exception of periodic hygiene management, contraception should be considered as a medical attitude to prevent unwanted pregnancy in women potentially having consensual sexual intercourse. In this view, the pertinence of tubal ligation in profoundly disabled women with severe associated motor impairment remains to be demon- strated, as well as for every woman who is not likely to engage in consenting sexual intercourse. Different factors specific to the intellectually disabled person may influence the choice of a given contraceptive method. We already evoked periodic hygiene management. Poor medical compliance, especially when associated with behavioral and/or psychiatric problems may question the efficacy of oral contraceptive agents. However, many intellectually disabled adults receive daily oral medication ( $45.8 \%$ in our study), that they take themselves or that is administered by a parent or caregiver. In this case, the compliance to oral contraceptive agent should not be considered. Another specificity of the persons with intellectual disabilities resides in the high prevalence of epilepsy. In our study, $26.4 \%$ of intellectually disabled women received daily anti-seizures medication. DMPA is currently reported to contribute to epilepsy stabilization, but evidence has, to our knowledge, not yet been reported. Amongst women treated for epilepsy, $74 \%$ daily received drugs that induce cytochrome P450 (carbamazepine, for instance), which reduces the efficacy of oral contraceptive agents. This should also be considered when initiating contraception in an intellectually disabled woman who suffers from epilepsy. Finally, abdominal surgery should be cautiously used in women with associated motor impairment, because of the increased frequency of postoperative complication. ${ }^{24}$

\section{General gynaecological care}

With some minor exceptions, intellectual disability does not lead by itself to specific gynaecological morbidity. Obesity and thyroid dysfunction, two common features in Down syndrome, may lead to anovulatory bleeding or frank menorrhagia. ${ }^{29}$ However, when comparing 15 adolescents with Down syndrome and 33 age-matched controls, Goldstein did not find any significant difference in cycle length or duration of bleeding between groups. ${ }^{80}$

Specific medical attitudes induced by the intellectual disability of the patients are likely to lead to a specific clinical picture. Because of the frequency of progestin intake by intellectually disabled women in Finland (to induce therapeutic amenorrhea), Huovinen ${ }^{25}$ reported an increased incidence of small uterus at pelvic examination in these patients when compared to a control group, but also fewer infections and tumors of all kinds in the group of persons with intellectual disabilities. Significant physical handicaps associated with intellectual disability, such as seizures, cerebral palsy or orthopedic problems significantly increase the risk of developing postoperative complications. ${ }^{24}$ In addi- 
tion, patients' fear, behavioral problems, or lower limb spasticity may complicate or delay complete physical examination, leading to significant delay in the diagnosis and treatment of pelvic diseases. ${ }^{24}$ Therefore, premedication before examination ${ }^{25}$ or a multidisciplinary approach in specialized clinics specifically designed for intellectually disabled patients have been advocated to better assess the reproductive health concerns of this population..$^{24,26}$

In conclusion, to support persons with intellectual disabilities' expectancies towards sexuality requires an evaluation of these expectancies and of the different patients' needs in the areas of contraception, hygiene management, sex education and STI or rape prevention. This may be achieved in specific facilities when available, but also by any gynecologist or general practitioner aware of the specificity of this population and working in collaboration with educative staff and parents to provide a global approach of sexual health concerns.

\section{References}

I. Brahams D. Sterilisation of a mentally incapable woman. Lancet 1989; I:1275-1276.

2. Dorozynski A. France to investigate illegal sterilisation of mentally ill patients. BMJ 1997;315:697.

3. Wolf $L$, Zarfas DE. Parents' attitudes toward sterilization of their mentally retarded children. Am J Ment Defic 1982;87:122-129.

4. Passer A, Rauh J, Chamberlain A et al. Issues in fertility control for mentally retarded female adolescents: II. Parental attitudes toward sterilisation. Pediatrics 1984;73:45I-454.

5. Elkins TE, Gafford LS, Wilks CS, et al. A model clinic approach to the reproductive health concerns of the mentally handicapped. Obstet Gynecol 1986;68:185-188.

6. Patterson-Keels L, Quint E, Brown D, et al. Family views on sterilisation for their mentally retarded children.J Reprod Med 1994;39:701-706. 7.Wheeless CR.Abdominal hysterectomy for surgical sterilisation in the mentally retarded :A review of parental opinion. Am J Obstet Gynecol 1975; 122:872-876.

8.Van Der Merwe JV, Roux JP. Sterilisation of mentally retarded persons. Obstet Gynecol Surv 1987;42:489-493.

9. Chamberlain A, Rauh J, Passer A, et al. Issues in fertility for mentally retarded female adolescents: I. Sexual Activity, sexual Abuse, and contraception. Pediatric 1984;73:445-450.

10. Meyerowitz JH. Sex and the mentally retarded. Med Aspects Hum Sex 1971;5:95-106.

II. David HP, Smith JD, Friedman E. Family planning services for persons handicapped by mental retardation. Am J Public Health 1976;66: 10531057.

12. Simonds JF. Sexual behavior in retarded children and adolescents. J Dev Behav Pediatr 1980;1:173-179.

13. Monat RK. Sexuality and the mentally handicapped. San Diego: College Hill Press. 1982.

14. Mc Gillivary JA. Level of knowledge and risk of contracting HIV/AIDS amongst young adults with mild/moderate intellectual disability. J Appl Res Int Dis 1999;12:1 13-126.
15. Servais $L$, Jacques D, Leach R, et al. Contraception of women with intellectual disabilities: prevalence and determinants. J Int Dis Res 2002;108-119.

16. Diederich N, Greacen T. Enquête sur la sexualité et la prévention du SIDA chez les adultes handicapés mentaux en lle de France. Revue Européenne du Handicap Mental 1996;3:20-32.

17. Gust DA,Wang SA, Grot J, et al. National survey of sexual behavior and sexual behavior policies in facilities for individuals with mental retardation/developmental disabilities. Am J Ment Retard 2003;5:365-373. 18. McCabe MP. Sexual knowledge, experience and feelings among people with disability. Sex Disabil 1999;17:157-170.

19. Pueschel SM, Scola PS. Parents' perception of social and sexual functions in adolescents with Down syndrome.J Ment Defic Res 1988;32:215-220.

20. Servais L, Luts A, Roussaux JP. L'instauration de la vie en couple des personnes handicapées mentales : Préalables, écueils et prise en charge. Acta Neurol Psychiatr Belg 1998; 12:282-292.

21. Patullo AW, Barnard KE. Teaching menstrual hygiene to the mentally retarded. Am J Nurs 1968;68:2572-2575.

22. Hamilton J,Allen P, Stephens L, Davall E. Training mentally retarded females to use sanitary napkins. Am J Ment Retard 1969;7:40-43.

23. Naivas MM, Braun SH.The use of operant techniques for modifying the behavior of the severely and profoundly retarded. Am J Ment Retard 1970;8:18-24.

24. Mc Neely SG, Elkins TE. Gynecologic surgery and surgical morbidity in mentally handicapped women. Obstet Gynecol 1989;74:155-158.

25. Huovinen K. Gynecological problems of mentally retarded women:A case-control study from southern Finland. Acta Obstet Gynecol Scand 1993;72:475-80.

26. Wingfield M, Healy D, Nicholson A. Gynecological care for women with intellectual disability. Med J Aust 1994;160:536-538.

27. Shet S, Malpani A.Vaginal hysterctomy for the management of the menstruation in mentally retarded women. Int J Gynaecol Obstet 1991;35:319-321.

28. Grover SR. Menstrual and contraceptive management in women with an intellectual disability. Med J Aust 2002; 176: 108-II0.

29. Elkins TE, McNeely SG, Punch M, et al. Reproductive health concerns in Down syndrome.A Report of eight Cases.J Reprod Med 1990;35:

745-750.

30. Kreutner K. Sexuality, fertility, and the problems of menstruation in mentally retarded adolescents. Pediatr Clin North Am 1981;28:475-480. 31. McCabe MP. Sex education programs for people with mental retardation. Ment Retard 1993;31:377-387.

32. Lindsay WR, Michie AM, Staines C, et al. Client attitudes towards relationships: Changes following a sex education programme. British Journal of Learning Disabilities 1994;22:70-73.

33. Servais L, Hoyois P, Roussaux JP. Sterilizing people with learning disabilities: a problem belonging to the past ? Eur J ment Dis 2000;2 1:4-16. 34. Servais L, Leach R, Jacques D, Roussaux JP. Sterilisation of intellectually disabled women. Eur Psychiatry 2004; 19:428-432.

35. Cambridge P. Men with learning disabilities who have sex with men in public places: mapping the needs of services and users in south east London.J Intellect Disabil Res 1996;40:24I-25I.

36. Lindsay WR, Law J, Quinn K, et al. A comparison of physical and sexual abuse: histories of sexual and non-sexual offenders with intellectual disability. Child Abuse Negl 200I;25:989-995.

37. Parry CJ, Lindsay WR. Impulsiveness as a factor in sexual offending by people with mild intellectual disability.J Intellect Disabil Res 2003;47: 483-487.

38. Lindsay WR, Lees MS.A comparison of anxiety and depression in sex offenders with intellectual disability and a control group with intellectual disability. Sex Abuse 2003;15:339-345. 
39. Streissguth AP, Bookstein FL, Barr HM, et al. Risk factors for adverse life outcomes in fetal alcohol syndrome and fetal alcohol effects.J Dev Behav Pediatr 2004;25:228-238.

40. Lindsay WR, Smith AH, Quinn K, et al. Women with intellectual disability who have offended: characteristics and outcome.J Intellect Disabil Res 2004:48:580-590.

4I. Lindsay WR, Smith AH. Responses to treatment for sex offenders with intellectual disability: a comparison of men with I- and 2-year probation sentences. J Intellect Disabil Res 1998;42:346-353

42. Jewkes R, Martin L, Loveday P.The virgin cleansing myth: cases of child rape are not exotic. Lancet 2002;359:7II.

43. Groce NE, Trasi R. Rape of individuals with disability:AIDS and the folk belief of virgin cleansing. Lancet 2004;363:1663-1664.

44. Smith C. The virgin rape myth: a media creation or a clash between the myth and HIV treatment? IASSCS International Conference on Sex and Secrecy, Johannesburg, South Africa, 2003;june 22-25.

45. Economic and Social Commission for Asia and the Pacific. Hidden sisters: women and girls with disabilities in the Asian Pacific region. New York, United Nations 1995.

46. Thompson D.The sexual experiences of men with learning disabilities having sex with men - issues for HIV prevention. Sex Disabil 1994; I2: $221-242$

47. Lunding S, Hansen KS, Krogsgaard K, et al. Occurrence of hepatitis B and $C$ among mentally retarded. Ugeskr Laeger 1999;161:4393-4396.

48. Devuyst O, Maesen-Collard Y. Hepatitis B in a Belgian institution for mentally retarded patients: an epidemiological study. Acta Gastroenterol Belg 1991;54:12-18.

49. Stehr-Green P,Wilson N, Miller J, et al. Risk factors for hepatitis B at a residential institution for intellectually handicapped persons. N Z Med J 1991;104:5|4-516.

50. Schoub BD, Johnson S, McAnerney JM et al. Hepatitis B virus prevalence in two institutions for the mentally handicapped. SAfr Med J. 1993;83:650-653

5I. Campins M, Orti R, Rossello J, et al. Infection with hepatitis B and C viruses in the mentally retarded. Enferm Infecc Microbiol Clin 1994;2: 134-136.

52. Cunningham SJ, Cunningham R, lzmeth MG, et al. Seroprevalence of hepatitis $B$ and $C$ in a Merseyside hospital for the mentally handicapped. Epidemiol Infect. 1994; I 2:195-200

53. Cramp ME, Grundy HC, Perinpanayagam RM, et al. Seroprevalence of hepatitis $B$ and $C$ virus in two institutions caring for mentally handicapped adults.J R Soc Med 1996;89:40I-402.

54. Arnedo Pena A, Latorre Ibanez MD, Pac MR, et al. Hepatitis A, B, and $C$ in an occupational center for the mentally handicapped. Enferm Infecc Microbiol Clin. 1998;6:370-373.

55. de Souza MM, Barbosa MA, Borges AM et al. Seroprevalence of hepatitis $B$ virus infection in patients with mental problems. Rev Bras Psiquiatr 2004;26:34-37.

56. Molsa PK. Hepatitis B carriers in a centre for the mentally retarded in Finland and immunogenicity of hepatitis B vaccine.J Ment Defic Res 1990;34:379-383.

57. Devlin JB, Mulcahy M, Corcoran R, et al. Hepatitis B in the nonresidential mentally handicapped population.J Intellect Disabil Res 1993;37:553-560.

58. Devesa F, Martinez F, Moreno MJ, et al. Hepatitis B markers at 3 open centers for mentally retarded. Rev Esp Enferm Dig 1993;84:162-168. 59. Ellis CE, Erb LJ, McKeown DJ, et al. Hepatitis B control in Toronto classrooms for the mentally retarded: a seroprevalence survey. Can J Public Health 1990;8I:I56-160.

60. Garcia O, Bruguera M, Mayor A, et al. Hepatitis B at an open institution for the mentally retarded. Immunogenic effect of a recombinant antihepatitis-B vaccine. Enferm Infecc Microbiol Clin. 1990;8: I48-152.
61. Di Ciommo V, Ferrario F, Rossi De Gasperi M et al. Epidemiology of hepatitis $B$ virus in non-institutionalized children and adolescents affected by handicap.J Intellect Disabil Res 1993;37:295-299

62. Pueschel SM, Bodenheimer HC Jr, Giesswein P et al. The prevalence of hepatitis $B$ surface antigen and antibody in home-reared individuals with Down syndrome. Res Dev Disabil I99|; I2:243-249.

63. Pincus SH, Schoenbaum EE, Webber M.A seroprevalence survey for human immunodeficiency virus antibody in mentally retarded adults. NY State J Med 1990;90:139-142.

64. Garcia F, Quiros E, Bernal M, et al. Ausencia de infeccion por VIH en deficientes mentales. Enferm Infecc Microbiol Clin 1991;9:516. 65. Marchetti AG, Nathanson RS, Kastner TA et al.AIDS and state developmental disability agencies: A national survey. Am J Public Health 1990;80:54-56.

66. Kastner TA, Nathanson RS and Marchetti AG. Epidemiology of HIV infection in adults with developmental disabilities. In Crocker AG, Cohen HJ, Kastner TA (Eds) HIV infection and developmental disabilities. 192:

127-|39. Baltimore: Brookes.

67. Ramos-Ibanez FM, Espino-Toquero C, Durontez-Nevarez A et al. SIDA et handicap mental: Une expérience d'intervention. Communication au $5^{\text {eme }}$ colloque européen de Noirlac, Noirlac, France, Octobre 1996. 68.Van Damme P, Cramm M,Van der Auwera JC et al. Horizontal transmission of hepatitis B virus. Lancet 1995;345:27-29.

69. Vellinga A,Van Damme P,Weyler J], et al. Hepatitis B vaccination in mentally retarded: Effectiveness after II years.Vaccine 1999;17:602-606. 70. Arnedo Pena A, Latorre Ibanez MD, Cortes Edo JM, et al. Diffusion of hepatitis $B$ among residents of an institution for handicapped children. Rev Esp Salud Publica. 1995;9:219-226.

7I. Rua Armesto MJ, Ramirez Marin V, Onaindia Ercoreca MT et al. Predisposition of Down syndrome to chronic infection with the hepatitis $B$ virus. An Esp Pediatr. 1993;38:529-531.

72. Heijtink RA, De Jong P, Schalm SW, et al. Hepatitis $B$ vaccination in Down's syndrome and other mentally retarded patients. Hepatology | 984;4:6 | I-6|4.

73. Ahman L, Back E, Bensch K, et al. Non-efficacy of low-dose intradermal vaccination against hepatitis $B$ in Down's syndrome. Scand J Infect Dis 1993:25:16-23.

74. Scotti JR, Nagle DW, Masia CL, et al. Providing an AIDS education and skills training program to persons with mild disabilities. Education and Training in Mental retardation and Developmental Disabilities 1997;32:113-128.

75. Lindsay WR, Bellshaw E, Culross G, et al. Increases in knowledge following a course of sex education for people with learning difficulties. J Int Dis Res 1992;36:531-539.

76. Zuhlke C, Thies U, Braulke I, et al. Down syndrome and male fertility: PCR-derived fingerprinting, serological and andrological investigations.

Clin Genet 1994;46:324-326.

77. Friedman JM, Sternberg WH,Varela M et al. Trisomy-2I in mother and child. Obstet Gynecol 1970;36:73I-734.

78. Bovicelli L, Orsini LF, Rizzo N, et al. Reproduction in Down syndrome. Obstet Gynecol 1982;9:13S-17s

79. Schulze A, Mogensen H, Hamborg-Petersen B, et al. Fertility in PraderWilli syndrome: a case report with Angelman syndrome in the offspring. Acta Paediatr 200I;90:455-459.

80. Goldstein H. Menarche, menstruation, sexual relations and contraception of adolescent females with Down syndrome. Eur J Obstet Gynecol Reprod Biol 1988;27:343-349. 